\title{
Appropriating Affordances. Three Practice Based Explorations
}

\author{
Tom Flint \\ Centre for Interaction Design \\ Edinburgh Napier University \\ t.flint@napier.ac.uk
}

\begin{abstract}
Affordance and Appropriation are related. An effective way of examining these phenomena is through practice. This paper discusses practice based exploration of affordance in the design of physical interfaces. This study follows a framework developed by Zimmerman et al (2007) based on Process Invention and Relevance. Three artefacts that explore affordance with tangible interfaces are presented. Aide Memoire demonstrates that what can be considered a simple and direct affordance may turn out to be a learnt affordance that only becomes simple through familiarity. The Homesick Aliens demonstrate the effectiveness of narrative in encouraging appropriation of a digital artefact. Giant Eyeballs demonstrates the direct appropriation of an affordance.
\end{abstract}

Affordance, Appropriation, Interactive, Art, Practice

\section{INTRODUCTION}

Using practice based research is an effective way of interrogating physical interfaces. The three case studies discussed in this paper all demonstrate the use of practice to inform research. Practice or research through design is gaining credibility in $\mathrm{HCl}$ research. Zimmerman et al (2007) describe this as iteratively developing artefacts

"in order to make the right thing: a product that transforms the world from its current state to a preferred state."

The phenomena investigated in this study are those of affordance and appropriation.

We understand affordance to be the experiential properties of objects that are concerned with use, for example we may be able to tell whether to push or pull a door from looking at. Appropriation is often understood as using artefacts in a manner that is contrary to their designed purpose. Designing with affordance in mind allows us to produce artefacts that are easy to use. Understanding appropriation enables us to cope when users misunderstand our designs and exploit them in an unexpected manner.

By constructing impactful interactive artwork, it has been possible to demonstrate some aspects of the link between appropriation and affordance. These links provide methods by which we may consider how we could design for appropriation, something that on the surface may appear to be oxymoronic (Dix 2007).

The structure of this paper initially discusses affordance and its importance to $\mathrm{HCl}$. This discussion is limited in that a full discussion of appropriation would fill a paper. This paper moves on to discuss appropriation as a philosophical concept, it's past understanding in terms of technology followed by its role in art. The hypothesis being that if we adopt an approach to appropriation from the art world this may help us to develop an alternative understanding of appropriation of technology.

Having introduced art, this paper moves on to discuss interactive art and its role in $\mathrm{HCl}$. The subsequent section argues for a practice based reflective approach to investigating interaction with technology. Using a framework from Zimmerman et al (ibid) three case studies are discussed each of which involved the design, construction and evaluation of artefacts that directly interrogate affordances.

\section{AFFORDANCE}

Gibson (1979) first discussed the concept of affordance and it was introduced to the $\mathrm{HCl}$ community by Norman (1988). Kaptelinin (2013) offers a detailed history of affordance and its relationship to $\mathrm{HCl}$. Compelling for this study is 
Kaptelinin's discussion of the Holmes stereoscope, a 3D image viewer and precursor of the Viewmaster $^{\mathrm{TM}}$ he tells us

"Even if you haven't seen a Holmes stereoscope before, you are likely to be able to use it almost immediately."

Affordances are tied to visual perception and can be described as properties of the experience of objects; affordances are specifically concerned with action on and with objects. When encountering a cup, it can be perceived from its form that it has the propensity to be used as a drinking vessel, a desk tidy or in a variety of ways.

Affordances exist as opportunities for an animal in terms of their bodily relationship with the world and it is through interaction with the world that affordances reveal themselves. In humans, particularly in the use of tools, is witnessed what can be perceived as a grouping together or bundling of affordances. As an example, when my office door is locked I need to exploit the combined affordances of a key and the door handle to open the door and sometimes the affordance of the bench next to the door to store my coffee cup while I perform this task. Perception of these 'complex' affordances (Turner 2005) can be brought together through 'coupling' (Dourish 2001). Perceiving affordances makes interactions 'ready-to-hand' (Heidegger 1927, Winograd and Flores 1987) and instinctive.

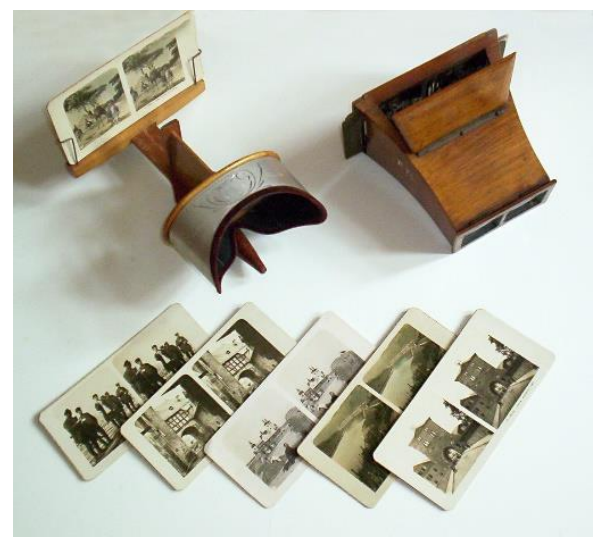

Figure 1: A Holmes' Sterescope Picture Source: Wikimedia Commons

Affordances can be argued to be the notion of "seeing as" (Flint and Turner 2016). At the moment of perception, we see the cup in terms of our motivation i.e. whether we need a drinking vessel or somewhere to store stationary. In the example of the Holmes stereoscope we perceive something to look through.

Affordance has been effectively employed in the design of user interfaces and has helped create more instinctive methods of interaction, Kaptelinin (ibid) gives examples from popular products such as tabs in website designs and sliders that emulate physical objects. However, the relationship with objects is not only concerned with immediate use, there are cultural and social values, perceived and implied, future use, ownership, a vast connected myriad of influences on sense making.

Pens afford writing, but an expensive fountain pen on someone else's desk has specific implications on use (Heft 2003), this is also true of computing technology, a PC in a University laboratory is free for anyone with an access code to use but a lecturer's personal laptop, although ostensibly belonging to the University as well, is not. The pen and the laptop have been appropriated and in this way appropriation directly disrupts the affordances of these artefacts.

\section{APPROPRIATION}

According to Borgman (1984) individuals are constantly appropriating the world around them. People perceive the use of technology as a method to

"bring the forces of nature and culture under control, to liberate us from misery and toil, and to enrich our lives" (ibid p.41).

To understand an idea, to appreciate art or to possess an object, are all acts of appropriation (Sartre 1943). This dimension of appropriation can be understood as extension of the self (Belk 1998). The relationship to the appropriated object is such that, although it exists in its own right, it is justified by its relationship to 'me.' Only through this relationship does the object have meaning.

McLuhan (1964) takes the notion of the extended self literally, stating, "All media are extensions of some human faculty - psychic or physical," wheels are extensions of the foot and clothing an extension of the skin. Merleau-Ponty (1945 p.165) discusses the blind man's stick as incorporated into the body; he makes similar claims for hats adorned with feathers and sense of intentions when driving a car, for him it is 'intentional threads' (ibid p.121) that link people to objects.

The ontology of the word appropriate is evolved from the Latin word appropriare; appropriare is derived from proprius, meaning "one's own" (Schneider 2003). Proprius is also the root of the word proper, the meaning of appropriate as an adjective.

\subsection{Appropriation of Technology}

Across computing literature, appropriation is presented as a phenomenon occurring at the end of the practice of adoption, a result of long-term use. Past studies of technology adoption have focused on a functional perception of technology use; this utilitarian point of view is born from a time when computer systems were expensive and typically for 
business. Much of the examination of the appropriation of technology has been centred on organisations, software or management information systems (Delaney et al 2008; De Sanctis \& Poole 1994, Orlikowski 1992 and 2000; Stevens 2009). This type of study focuses on adoptive practices of people in organisations that have had systems or technology introduced as part of their work practices. The focus here is on a finished product that is then adapted for use by human agents. Jennie Carroll (2004) presents appropriation as a process that relieves the tensions between technology as designed and technology in use but the increasingly personal nature of technology has revealed appropriation as a social, collaborative practice (Dourish 2003, Bodker 2012).

\subsection{Appropriation in art}

Appropriation, in the sense of re-contextualising, is seen as a method of having dialogue with other works of art and or important cultural concepts. When street artist Banksy produced a series of screen prints of Tesco 'value' soup tins, his work would have had little meaning without Warhol's famous depictions of Campbell's soup tins, an act of appropriation itself. What can be learnt from the art world is that appropriation is relevant cultural practice.

Adapting and repurposing the world and artefacts is a way of holding cultural discourse and extending the meaning of an image or artwork. Trisha Ziff (2006) highlights the appropriation of imagery to communicate ideas. By concentrating on the history, use and appropriation of a single image she discusses the ability of artists and designers to employ this image as a short hand for a concept. The image she discusses is the well-known portrait of Che Guevara taken by Alberto 'Korda' Diaz on 5th March 1960. This image has become an icon used across the world to represent revolution and nonconformity

\footnotetext{
"The familiar image can be customised to suit any individual, any protest, and can disseminate a message that's instantly recognizable and has an ever-potent visual currency" (ibid p.14).
}

This example of the Che Guevara image is an example of what Dawkins (1976) refers to as meme replication. This sense of ownership and the ability to communicate ideas with appropriation challenges the traditional $\mathrm{HCl}$ view of appropriation as adoption. $\mathrm{HCl}$ responds to available technology and within the personal computing industry technology change is rapid. As a response to the paradigm change in personal computing a 'third wave' of $\mathrm{HCl}$ (Bodker 2006, Hurtienne 2009) has adopted a phenomenological, embodied approach to technology use.

\section{INTERACTIVE ART}

Edmonds (in Candy and Ferguson 2014 p.12) tells us

\begin{abstract}
"Issues relating to Human-Computer Interaction $(\mathrm{HCl})$ could be considered to be as important to interactive art creation as issues relating to the colours of paint are to painting."
\end{abstract}

$\mathrm{HCl}$ has a specific interest in interactive art as borne out by special interest groups such as SIGCHI Creativity Cognition and collaborative conferences like Reactor(3) at British $\mathrm{HCl} 2008$. One of the advantages of studying interactive art is that it concerns itself specifically with interaction, countering the constraints of functionality (Bullivant in Rodgers and Smith 2010 p.196).

Snibbe (2009) offers guidelines on designing aesthetic interactive work. Snibbe is of note because his work is both prolific and successful in terms of public commission. Snibbe presents a model (see Error! Reference source not found. 2) that looks something like an onion with philosophy at the core and exhibition content as the skin.

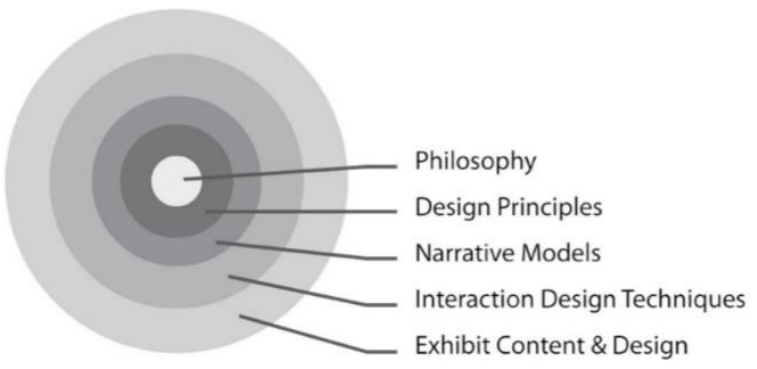

Figure 2: Snibbe's model for designing users' interactions with socially immersive media.

Edmonds (in Candy and Edmonds 2011) proposes that work should be considered in terms of Attractors, those phenomena that make people want to interact with the work, Sustainers, phenomena that maintain interaction over time and Relators, phenomena of the work that cause reflection and create a desire for repeated experience.

\subsection{Interactive Art as Research}

Schön (1983) argues that tacit knowledge produced through practice is important in terms of gaining new understanding of a subject. This type of knowledge has a different form and structure to typical empirical evidence and can be difficult to impart successfully. Lizzie Muller (in Candy and Edmonds 2011) argues that we need to consider reflection in action and reflection on action. The former occurs as an undocumented activity occurring during manipulation of materials and the latter is able to be 
documented at opportune points in the activity, allowing the practitioner to reflect on the process in hand.

Muller (ibid) describes how she used reflection to discuss curatorial practice in digital arts in her PhD thesis for the Creativity and Cognition Group. This alludes to this approach being accepted practice in the interactive art community but it can be demonstrated that this approach is in use across the fields of Interaction Design and HCI (Fallman 2008, Zimmerman et al 2007). Sengers et al (2005) tell us that reflective practice is linked to critical reflection allowing a

\section{"truly experience focused approach."}

Dalsgaard and Halskov (2012) offer a framework for reflective design documentation, this framework records events and sub events in a linear manner, attempting to expose the questions responded to in the practice of design. Design knowledge is revealed in action (Schön 1992) and it is the artefacts themselves that are the output of research. Simply presenting artefacts is insufficient; work needs to specifically address research questions in context that are to be explored and questions of impact have to be justified.

Zimmerman et al (2007) offer a framework for Research Through Design specifically aimed at $\mathrm{HCl}$. This framework focuses on Process, Invention and Relevance. Process discusses the physical development of the product under investigation. This is important because there are often many stakeholders involved all with competing motivations. Practice can often be an absorbing process that involves making and production through intuitive acts that are hard to impart after the fact. Invention considers the novelty of the artefact produced and how it interrogates the subject under discussion.

Relevance is particularly important and is concerned with where the artefact has been exhibited, how many people have interacted with it and what if any impact it may have had in the wider world. This aspect of practice based research is particularly relevant in terms of public engagement, by displaying these works we can exhibit university research. Bilda et al (2008) offer a Creative Engagement Model that discusses how to implicitly design interactive art for participant engagement.

\section{THREE PRACTICE BASED CASE STUDIES}

This paper has introduced affordance and appropriation claiming they are linked and made an argument for reframing our understanding of technology appropriation in terms of the understanding of appropriation in art. We have made an argument for exploring interaction, affordance and appropriation through the production

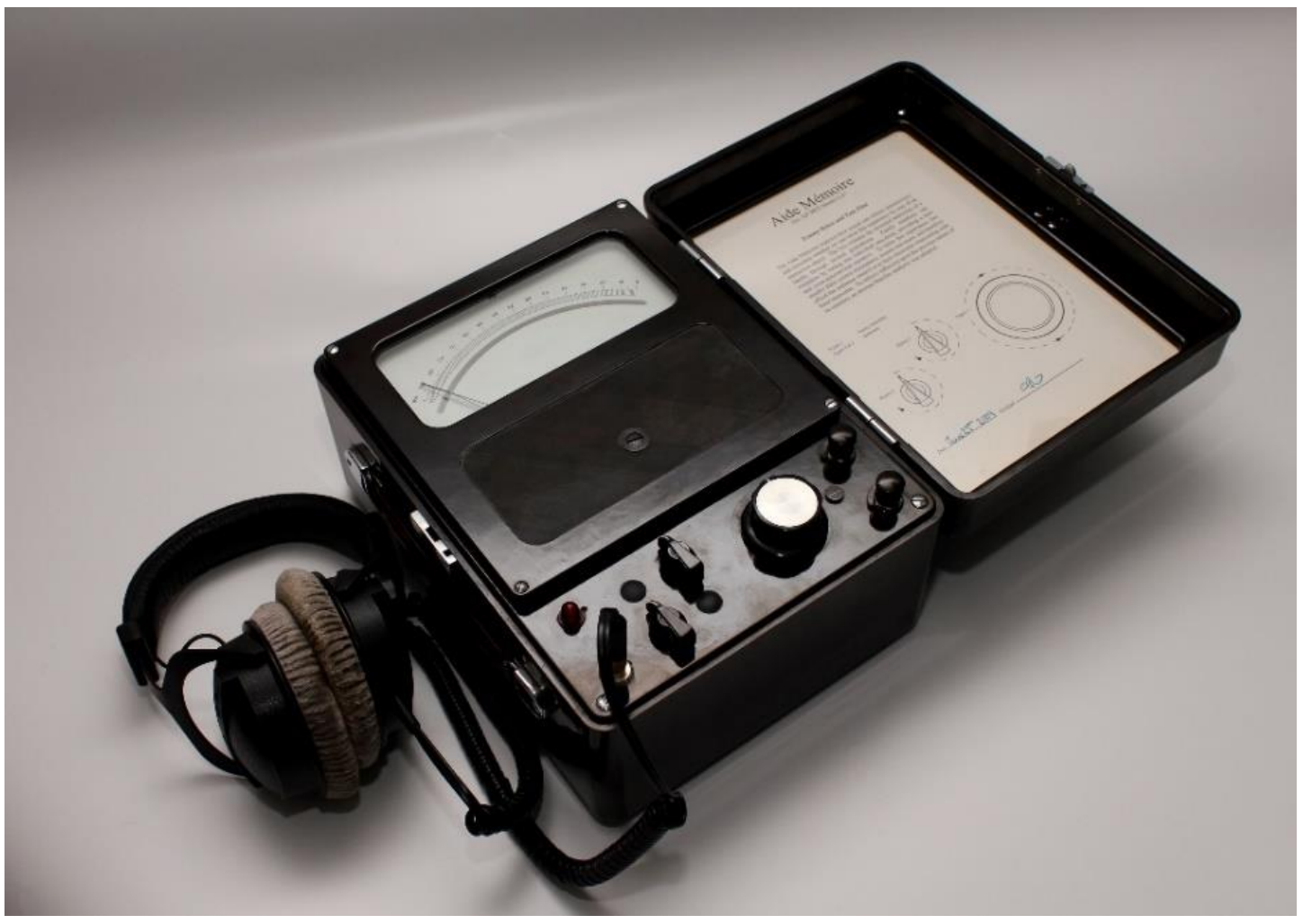

Figure 3: Aide Memoire 
of interactive art. We now turn to a discussion of three artefacts that were built to interrogate affordance and appropriation. All three artefacts were put on display in significant public fora. This section utilises Zimmerman et al's framework of Process, Invention and Relevance to discuss these phenomena

\subsection{Aide Memoire}

The Aide Memoire was born out of a series of creative sessions with designer Tommy Dykes and is a collaborative work. A fictitious service company was devised that would visit, interview and record the memories of members of a family. Edited versions of these memories would be stored in a device and made available to members of that family. It was felt important that the physical object have the appearance of a family heirloom, handed down from one generation to the next.

\section{Process.}

The Aide Memoire is constructed from out of date testing equipment shown in Figure 3 The large look and feel of the equipment was hoped to evoke the sense of a past that is made of mechanical, tangible technology. Using an embedded Arduino communicating with software written in Max/MSP the object was appropriated and repurposed.

The aesthetic of the product is a product of bricolage, the engineering school at our university discarded a large quantity of pre-transistor equipment, and this specific box was felt to have a suitable look and feel. As a repurposed object it was not possible to enforce complete control over the knobs and dials. Despite there being what were considered obvious knobs for interaction, many people would try to use the connection screws to interact with the object. Participants were also more forceful than expected, for example the main tuning dial is controlled by a ten-turn potentiometer. This is a potentiometer that will turn ten times and no more, several people were observed attempting to force the dial to turn further. Comments from participants were that the lack of visual feedback on the original device left them confused.

Taking observation and comments from initial exhibition into account, a second iteration of the artefact was produced. A servomotor was added that controlled a needle on the front of the box. The needle's movements were proportionally connected to the movement of the main dial. Finally a set of instructions were produced and placed inside the open lid of the box. Great care was taken to make the instructions in keeping with the aesthetics of the box itself.

\section{Invention}

Aide Memoire exposed participant behaviour toward objects and the elusive nature of what a designer might consider simple affordances. One of the more surprising discoveries was the unfamiliarity of participants with the action of the ten-turn potentiometer. In the design sessions, this was felt a natural affordance because of the team's familiarity with analogue radios and the knob's similarity to a tuning dial. It was incorrectly believed that this was intuitive; in fact, it is a learnt interaction and young people who are unfamiliar with analogue radios need to be introduced to the concept.

\section{Relevance}

The first iteration of Aide Memoire was exhibited at the 2009 Sonica Festival of sound and audiovisual experimental arts in Ljubljana Slovenia. The Sonica exhibition ran throughout the month of June at Gallery Jakopič in the city centre. After this event, the second iteration was constructed adding functionality. The second iteration was displayed at Create ' 09 held at the BCS in London and Creative Cultures '09 held at Edinburgh Napier University. The Aide memoire has also been shown at Edinburgh Mini Maker Faire 2013, 2014, 20152016 and 2017 it is also on display in the Interactions gallery at British $\mathrm{HCl} 2017$.

\section{Appropriation and Affordance}

Appropriation was an essential component of this piece. The outer form of the artefact was an appropriated piece of testing equipment. The physical interaction of using a tuning dial was appropriated from radio tuning dials. This piece specifically demonstrates issues with perceiving affordances. The affordance of a tuning dial was revealed to be a complex, learnt affordance. This e revelation of a learnt affordance was only exposed during display and testing.

The affordance of tuning was successfully appropriated from tuning dials demonstrating that the direct appropriation of an affordance is possible much in the same way that non conformity can be appropriated by using the image of Che Guevara.

\subsection{Homesick Aliens}

The Homesick Aliens were initially produced for an event in 2010. They were developed considering the effect of narrative on engagement with technology. Five aliens were made using the soft toys known as Ugly Dolls ${ }^{\mathrm{TM}}$. A story was developed for the dolls whereby they had been discovered on Earth and were unwell. Participants would be encouraged to 'code them better.' Each doll has an Arduino Lilypad attached to the area where one might expect to find a human's heart. This Lilypad was then attached to electronic devices, used to advance a narrative . 


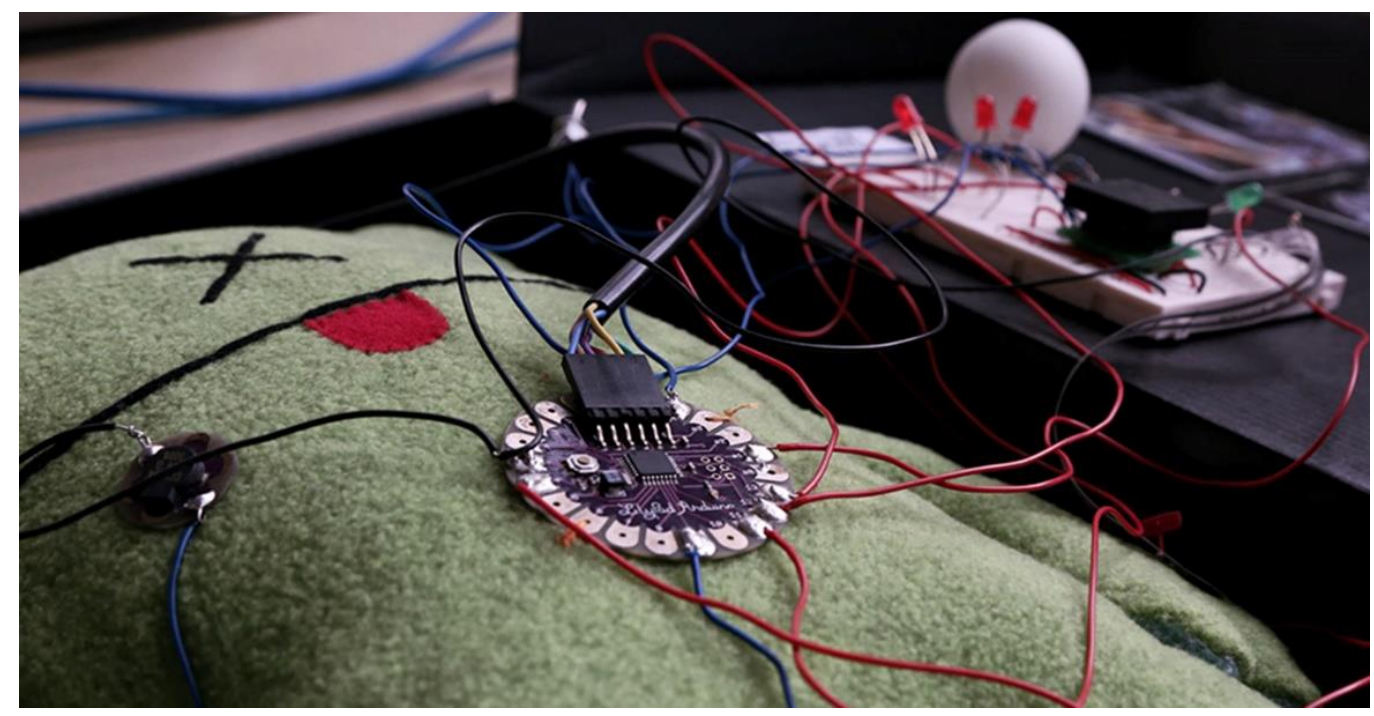

Figure 4: A Homesick Alien

Participants are tasked with discovering what the alien likes to eat, it's favourite colour and how to comfort the alien by holding its hand at just the right pressure. Food is emulated with RFID cards. There are several cards, each with a picture laminated onto them. Pictures were of a variety of objects, a mouse, ice cream and a pile of rubbish being some examples. By presenting the RFID card to the alien, it is possible to discover which food it preferred. Feedback is given by three red LEDS, each one will light up when a correct input is made.

An RGB LED covered with a ping-pong ball represents the aliens' favourite colour. These are presented as mysterious orbs and participants need to alter the RGB settings in code presented on a laptop. Setting the correct code makes a red LED turn on. Colour clues are on the reverse of the RFID cards and colours have to be entered in hexadecimal, affording a discussion on number conversion; conversion software is provided. With the colours on the screen, the RGB LED and the rear of the RFID card, it is possible to have a conversation about cross platform colour fidelity.

A force sensor is used to represent holding the aliens' hands. Once all three inputs are correct, a speaker sewn next to the alien's mouth produces a tune. Because all of these inputs and outputs are programmable, aliens are usually coded to "like" different things and "sing" different songs. Once a participant has successfully made an alien sing, they are then encouraged to repurpose the code and change the parameters that make the alien sing. Participants are also able to change the tune the alien sings.

\section{Process}

Production of the Homesick Aliens was a solo process, the imperative was initially to create a quick and easy entry to programming. It was believed that the form of the Ugly Dolls would be a means to quickly engage young people. Initially different forms of technology were explored whilst teaching a module in physical computing. This exploration led to strong familiarity with these technologies.

The narrative was developed using the various affordances of the technologies such as the RFID cards and was a method to master the use of these technologies. The first doll was developed as a rough prototype with a view to creating a more finished piece. Once the first doll had the Arduino Lilypad attached with connected wires it was reminiscent of a person on a life support system. This view prompted the narrative and the various technologies were adapted to afford telling the story of a homesick alien.

\section{Invention}

The Homesick Aliens have proved to be an excellent medium for starting conversations with young people about physical computing. Using the narrative means that programing and computing concepts can be presented in an informal manner. The combined approach of the inputs has meant that the aliens can be adapted for their audience. For example, very young children can simply be asked to find the right food to make the alien sing.

Most people appear to engage with the dolls on sight. It is likely that this is due to the appealing nature of the Uglydolls themselves. Many people make sympathetic comments directed at the dolls; they have been dressed to appear as if they are on a form of life support machine. The combination of the doll's appearance and the life support emulation encourages anthropomorphism.

As the dolls are often displayed at community events such as Maker Faires, it means that people are time constrained in their interactions. They are often in 
groups and will be pressured to move on. It can be argued that the dolls conform to Edmonds' (in Candy and Edmonds 2011) framework of attractors, sustainers and relators. The attractor is their physical appearance; the sustainers are the narrative and the acts of coding. The relators are repurposing and adapting the dolls through programming. People have often been witnessed returning for repeated interaction.

The use of narrative to engage people with these unfamiliar concepts is effective. The dolls stand up robustly to repeated use remaining relevant for over five years and are still used in discussion at many levels. They would benefit from being complemented with a more focused study. Time and resource constraints have not allowed further study so far.

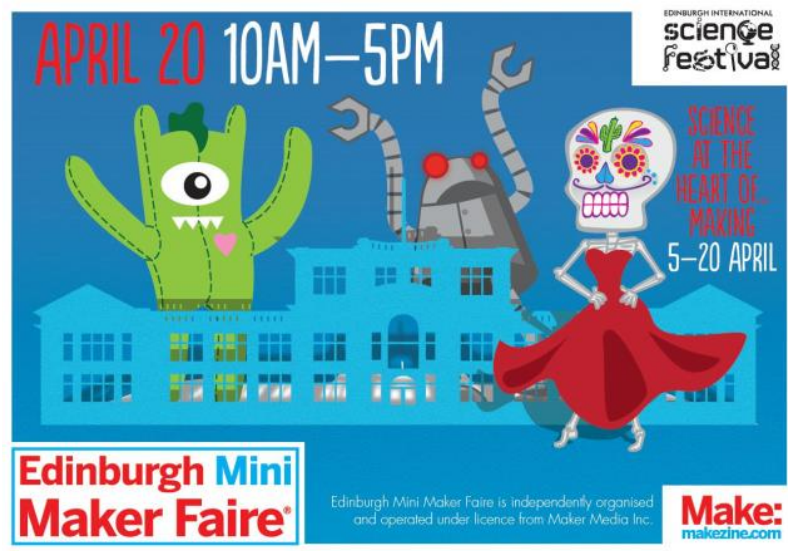

Figure 5: Mini Maker Faire Promotional Material Relevance

The Homesick Aliens have been regular attendees at various events for the school to which the author is allied. They have also been presented at Edinburgh Mini Maker Faire 2013, 2014, 2015 and 2016. Edinburgh International Science Festival run the Mini Maker Faire and included several pictures of the aliens in their 2013 brochure, they have also inspired a character on promotional material (Figure 4).

\section{Appropriation}

Appropriation is a key factor of the Homesick Aliens, the dolls are popular soft toys and their form has been appropriated in an effort to quickly establish empathy from children. During participation workshops children are encouraged to adapt and alter the software to their own ends. It can be argued that participants appropriate the dolls in their activities. They are given the ability to exploit the affordances of the technology through programming. This can be viewed as coupling these affordances through appropriation. Once children have performed this appropriation their imperative is to reprogram the dolls, ignoring the canonical functions and story; manifested in actions such as creating patterns with the lights and working to compose versions of popular songs from the speakers. This is appropriation through repurposing or something we like to call creative misuse.

\subsection{Giant Eyeballs}

Giant Eyeballs is an installation constructed for the Edinburgh International Science Festival 2014. This work was part of an exhibition titled Making It. Making It was held in the Grand Gallery at the National Museum of Scotland from the 5th to the 20th April 2014, Ocean Terminal shopping centre from the $4^{\text {th }}$ to the $19^{\text {th }}$ April 2015 and The Centre Livingston Saturday 26th May to Sunday 10th April 2016. The overall aim of the exhibition was to communicate the success of Maker culture.

Participants interact by looking through white peepholes. A camera points at their eye and they see an enlarged image of that eye on a monitor behind the peepholes. A series of red dots are drawn onto the image of their pupil, moving as their eye moves.

The movement of their pupils also affect sound files embedded in the software. Two large monitors sit on top of the stand; an embedded light sensor changes the image on the monitors as a participant puts their head up to the peephole. In its rest state the monitor attracts people with moving text encouraging them to "take a peek". When a participant is looking through the peephole, their eye is projected on the monitor. There are two peepholes and use of both of them often results in the display of two eyes that move independently from each other.

\section{Process}

The Science Festival were keen to communicate the story of Temptone, a graffiti writer publisher and activist. Temptone was diagnosed with Amyotrophic Lateral Sclerosis, resulting in him being completely paralysed, only able to move his eyes. A group of technologists constructed a method of analysing the movement of a person's pupils with a Sony Playstation camera. The instructions and software for this project were published online.

Design of the installation began with an approach from Matt Wright of the Science Festival. Initially a cardboard box with a peephole was constructed. A camera was placed in the peephole and connected to pixel tracking algorithms and a tone generator in Max/MSP, this resulted in being able to control tones with the movements of one's eye. A series of prototypes were constructed refining the artefact over time

Yann Seznec, a renowned musician and interactive artist was approached to collaborate on sound and 


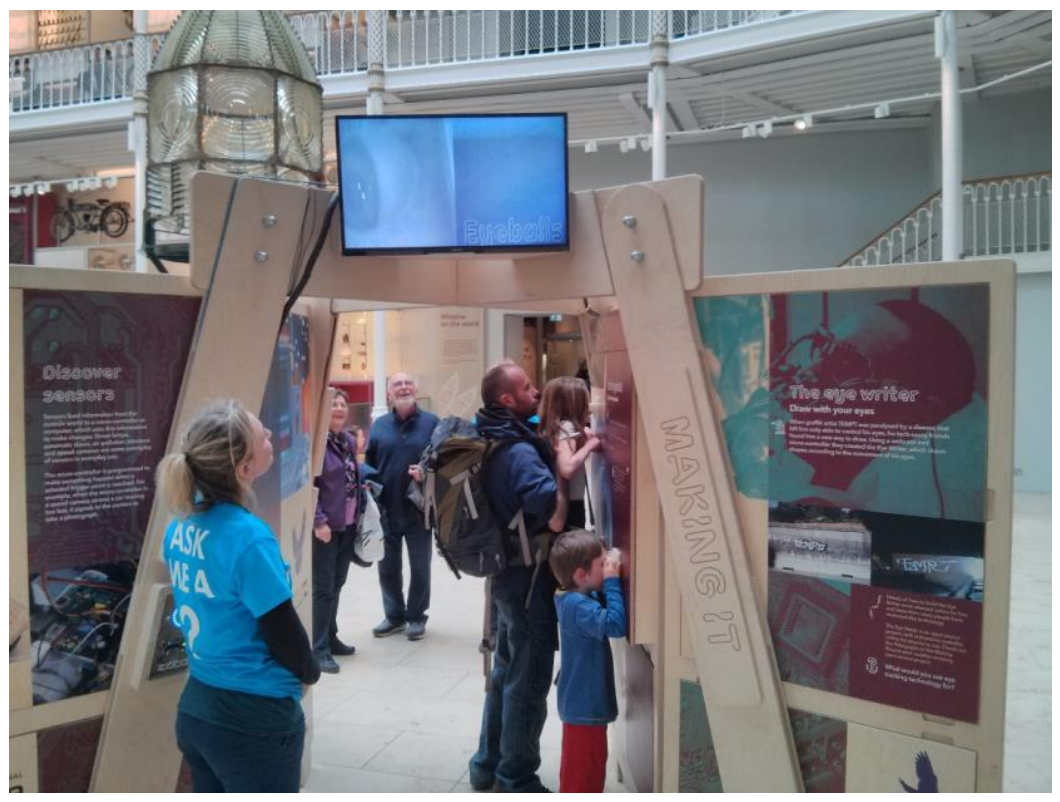

Figure 6: Giant Eyeballs

visual production, he also contributed to GUI design for science festival operators.

Edmonds' framework of attractors, sustainers and relators was considered from project inception. The monitors were considered the attractors, particularly with their call to 'take a peek.' The sustainer was the eye interaction itself and the relators were considered to be the narrative of Temptone and discussion of the exhibit amongst families.

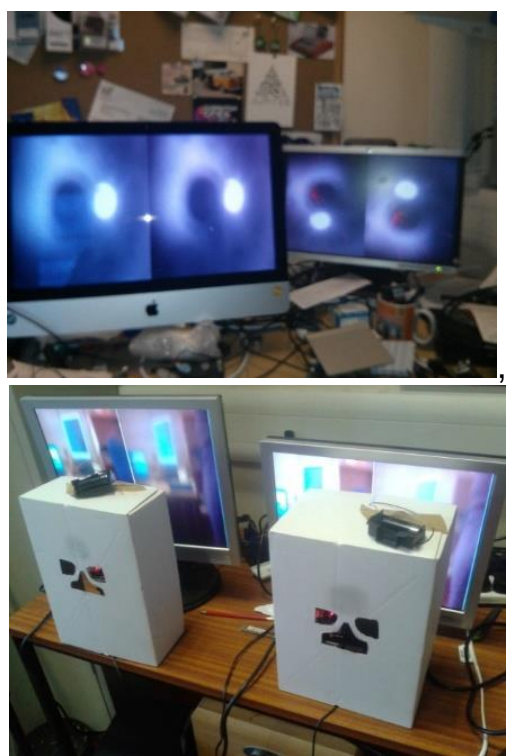

Figure 7: Early hardware and software prototypes

\section{Invention}

One major concern in the design process was the creation of a simple affordance for the peepholes. Early prototypes had used cut out holes and the tubes from inside toilet rolls as peep holes. Considering the issues with the tuning interaction with the Aide Memoire, it was felt that the use of a familiar object or shape was important. Objects that encouraged and afforded peeking were considered such as cameras and binoculars and it was considered that binoculars were suitably familiar objects. In order to create the binocular shape, a second-hand View-Master ${ }^{\mathrm{TM}}$ was purchased and scanned with a 3D scanner. The resulting 3D model was subsequently altered, including space for the light sensor and printed with a 3D printer. In this way the affordance of looking through was appropriated from the View-master.

\section{Relevance}

The grand gallery at the National Museum of Scotland is a high-profile exhibition space in Edinburgh that achieves a large volume of visitors. The Making It exhibition was featured on STV news and was well publicised by the Science Festival. The 2015 and 2016 display were in major shopping centres in Edinburgh and Livingston with a high footfall.

\section{Appropriation}

Appropriation as a theme was discussed during the design phase and it was felt that allowing the participant control through their eye movements would establish interaction as a personal event. The tracking software was not as accurate as desired, meaning that participants could not obtain intended control as discussed by Bilda et al (2008). However, this did not appear to be a specific barrier to participants' enjoyment of the work. Providing audio and visual feedback to eye movements was enough to keep people engaged. This 
demonstrates that it is not how interactive the object is but how interactive the participant perceives it to be that creates engagement.

Some observation was conducted on site and interesting repeated activities revealed themselves. No formal analysis was conducted and what follows are anecdotal observations from notes taken at the time. Many people referred to the large images of the eye as disgusting. Repurposing was observed, where some children stuck their tongues into the peephole. This then meant that their tongues would appear enlarged on the monitor. Participants resolved the issue of a lack of fine control through blinking to create sounds; this did create a more evident effect than attempting to use eye movement.

Conversations with Science Communicators manning the artefact in 2014 and observation revealed that older people were keen to gain an understanding of the technology. During observation, communicators often took advantage of having a designer on location to direct visitors to for further explanation. It was clear that people needed guidance to observe the large screens and did not necessarily make the connection that the eyes on the screen were the eyes of those participating. This is described in a report from Scotinform thus (the tunnel area is where the peep holes were located):

- Visitors did not tend to look up at video screens unless advised by Science Communicators to do so.

- Visitors did not spend too much time within the "tunnel" area of the pod unless the Science Communicators were engaging with them and explaining the content.

A noteworthy observation is demonstrated in Figure 6. All the people in this picture are from one family group and they are adopting a common stance witnessed in other participants. What was observed was a desire to interact from children. This is a common observation in interactives of any type, where children will be keener to engage. In this picture, it is possible to observe a father helping the children to take part in the action of peeking. The grandparents are standing back and observing activity as a whole. This is elaborated on in the discussion section.

\section{DISCUSSION}

Building these three interactive artefacts respond to different motivations. The Aide Memoire was a specifically personal piece of work that was designed for lone interaction. The experience of the artefact is difficult to share except through discussion. The overall response to the piece is positive and it succeeds in creating a reflective experience based around reminiscence.

The main discovery from the Aide Memoire was that understanding of affordances is much more nuanced than assumed. This was revealed in misunderstanding of the tuning dial. What appears to be a simple or instinctive affordance can be revealed to be a learnt affordance and it is important to consider this in design.

The Homesick Aliens have proved to be a successful artefact for encouraging young people to learn to code. These artefacts have now been experienced by hundreds of individuals with highly positive results. The use of narrative and their adaptability allows participants to appropriate these dolls fully.

Young people have been witnessed appropriating the aliens by creating their own stories, using them and recoding them accordingly. These artefacts afford repurposing through coding and can be claimed to be extremely successful in their current iteration.

The aliens also encourage further understanding of physical computing allowing full control of their functionality. Their narrative and physical appearance allows children to anthropomorphise them. The affordances of the various attributes of the dolls are complex and require coupling to be fully understood. Through appropriation children make sense of the coupled affordances and discover their own ways of interacting with the technology.

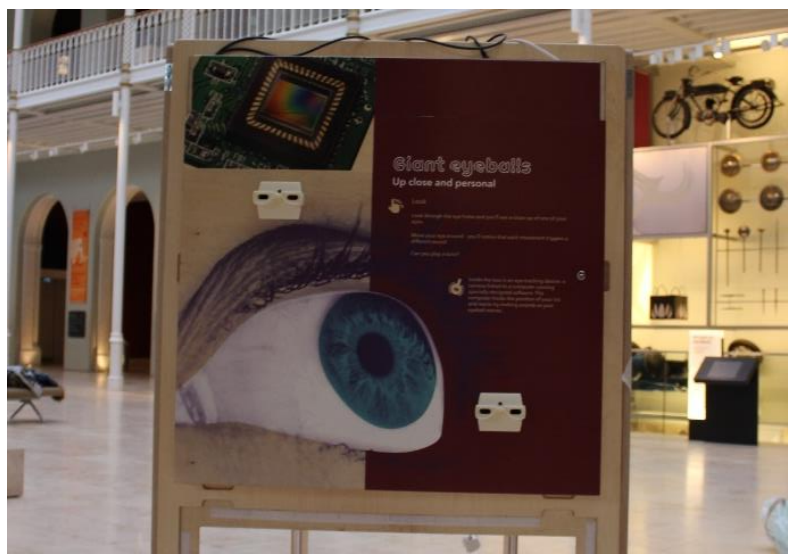

Figure 8: Giant eyeballs Main Panel

Giant Eyeballs are a successful adaptation of Edmond's framework of attractors, sustainers and relators. Through observation and an official report, a great deal has been learnt about the experience of group interaction. In Giant Eyeballs there has been repeated observation of cross-generational reaction to interactive work.

A major lesson learned from Giant Eyeballs was the direct appropriation of an affordance. The author was unaware of Kaptelinin's example of the Holmes 
stereoscope before producing this piece of work. The View-master is an evolution of the Holmes Stereoscope. It can be seen in figure 8 that we used 3D scans of a View-master on the main panel for Giant Eyeballs. In this way, we have managed to employ the shape of the View-master much in the way that Ziff discusses the appropriation of the image of Che Guevara.

Considering the family group interaction demonstrated in Figure 6; It is a common pattern to observe parents acting as facilitators of children's active engagement with technology and older people happy to observe others rather than taking part. Weiss et al (2009) in a study conducted with Aibo robotic dogs discuss similar findings, they link this to Norman's (2005) three levels of emotion. It is possible to consider older members of the public engaging reflectively, whereby they stand back and observe, gaining an understanding of the artefact on display.

\section{CONCLUSIONS}

A potential conclusion is that if it is possible to successfully design for participant engagement then perhaps it is necessary to model work that, affords cross generational activity. This implies that a successful interactive should be engaging for people to observe others, allow people to actively help younger people interact and be accessible to younger people and children.

This paper demonstrates practice as an effective means of investigating affordance and appropriation. It has been demonstrated both in the Aide Memoire and Giant Eyeballs that an affordance can be directly appropriated in the manner of an image. This begs the question of whether we can legitimately place affordance in a similar category to semiotics. This would of course be the subject of further investigations.

\section{FURTHER WORK}

The success of these practice based explorations encourages further production of interactive artwork. It is planned that the use of narrative to encourage appropriation will be employed in a new iteration of the Homesick Aliens. The aliens continue to be employed in publicity for the Edinburgh Mini Maker Faire and this has prompted the desire to produce a more robust piece with the development of a narrative to encourage interaction.

The exploration of affordance and appropriation through physical artefacts continues to be an important theme that will be explored in the future.

\section{REFERENCES}

Belk, W. (1988). 'Possessions and the Extended Self'. Journal of Consumer Research, 15(2), 139168.

Bilda, Z, Edmonds, E, \& Candy, L. (2008).' Designing for Creative Engagement'. Design Studies, 29(6), 525-540.

Bodker, S (2006) 'When Second Wave HCl meets Third Wave Challenges'. Paper presented at NordiCHI 2006 Oslo, Norway.

Bodker, S. (2012). 'Poetry in motion - Appropriation of the world of Apps'. Paper presented at ECCE 2012, Edinburgh UK.

Borgmann,A. (1984). 'Technology and the Character of Contemporary Life'. The University of Chicago Press, Chicago.

Candy, L, \& Edmonds, E. (2011). 'Interacting: Art, Research and the Creative Practitioner'. Libri Oxfordshire.

Candy, L and Ferguson, S (eds) (2014) 'Interactive Experience in the Digital Age' Springer Cham Switzerland.

Carroll, J. (2004). 'Completing Design in Use: Closing the Appropriation Cycle'. Paper presented at the European Conference on Information Systems, Turku, Finland.

Dawkins, R. (1976). The Selfish Gene. Oxford University Press Oxford.

Delaney, P, Timbrell, G, \& Chan, T. (2008). 'A Marxian Model of Technology Appropriation'. Paper presented at the JAIS Theory Development Workshop.

DeSanctis, G , \& Poole, M. (1994). 'Capturing the Complexity in Advanced Technology Use: Adaptive Structuration Theory'. Organization Science, 5(2), 121-147.

Dix, A (2007) 'Designing for appropriation.' Proceedings of the $21^{\text {st }}$ British $\mathrm{HCl}$ Group Annual Conference on People and Computers.

Rodgers, P, \& Smyth, M (Eds.). (2010). 'Digital Blur Creative Practice at the Boundaries of Architecture, Design and Art'. Libri London.

Dalsgaard, P and Halskov, K (2012) 'Reflective Design Documentation' .Paper presented at DIS 2012 Newcastle UK.

Dourish, $\mathrm{P}$ (2001) Where the Action is: The Foundations of Embodied Interaction. Massachusetts: MIT Press.

Dourish, P. (2003). 'The Appropriation of Interactive Technologies: Some Lessons from Placeless Documents'. Computer Supported Cooperative Work, 12(4), 465-490. 
Fallman, D (2008) 'The Interaction Design Research Triangle of Design Practice, Design Studies, and Design Exploration'. Design Issues 24(3) pp 4-18.

Flint, T. \& Turner, P. (2016) 'Enactive Appropriation'. Al \& Society Volume 31 Issue 1 pp 41-49.

Gibson, J (1979) The Ecological Approach to Visual Perception. Lawrence Erbaum Associates, London.

Heft, H. (2003). 'Affordances, Dynamic Experience, and the Challenge of Reification'. Ecological Psychology, 15(2), 149-180.

Heidegger, M. (1927). Being and Time. Blackwell Oxford.

Hurtienne, J (2009) 'Cognition in $\mathrm{HCl}$ : An Ongoing Story'. Journal of Human Technology 5 (1) pp 1228.

Kaptelinin, V (2013) 'Affordances in The Encyclopaedia of Human-Computer Interaction $2^{\text {nd }}$ Edition'. The Interaction Design Foundation Aarhus. https://www.interactiondesign.org/encyclopedia/affordances_and_desig n.html

McLuhan, M. (1964). Understanding Media (2002 ed.). Routledge London.

Merleau Ponty, M. (1962). Phenomenology of Perception: an Introduction. Routledge London.

Norman,D (1988) The Psychology of Everyday Things. Basic Books New York.

Norman, D. (2005). Emotional Design, why we love (or hate) everyday things. Basic Books New York

Orlikowski, W. (1992). 'The Duality of Technology in Organisations'. Organization Science, 3(3), 398427.

Orlikowski, W. (2000). 'Using Technology and Constituting Structures: A Practice Lens for Studying Technology in Organizations'. Organization Science, 11(4), 404-428.

Sengers, P, Boehner, K, Shay, D, Kaye, J (2005) 'Reflective Design'. Paper presented at CC05 Aarhus Denmark.

Sartre, J-P. (1943). Being and Nothingness. Routledge: Bristol.

Schön, D (1983) The Reflective Practitioner. Basic Books: New York.

Schneider, A. (2003). 'On 'appropriation'. A critical reappraisal of the concept and its application in global art practices'. Social Anthropology, 11(2), 215-229.

Snibbe, S, \& Raffle, H. (2009). 'Social Immersive Media: Pursuing best practices for multi-user interactive camera/projector exhibits'. Paper presented at $\mathrm{CHI} 2009$, Boston.
Stevens, G. (2009). 'Understanding and Designing Appropriation Infrastructures: Artifacts as boundary objects in the continuous software development.' (PhD), University of Siegen, Germany.

Turner, P (2005). 'Affordance as Context.' Interacting with Computers, volume 17 pp 787800.

Weiss, A, Wurhofer, D, Tscheligi, ' $M$ "I Love This Dog"- Children's Emotional Attachment to the Robotic Dog AIBO'. International Journal of Social Robotics 1 (3) pp243-248.

Winograd,T, \& Flores,F. (1987). 'Understanding computers and cognition: a new foundation for design'. Addison-Wesley Reading Mass.

Ziff, T (Ed.). (2006). Che Guevara: Revolutionary \& Icon. V\&A London.

Zimmerman, J, Forlizzi, J, Evenson, S (2007) 'Research through design as a method for interaction design research in $\mathrm{HCl}$.' Paper presented at CHI07 San Jose USA. 